\title{
Üropatojenlerde Antibiyotiklere Direnç Durumu: Sık Kullandığımız Ajanlar Etkili mi?
}

\author{
Aslı KARADENİ, Aziz Ahmad HAMidí \\ Maltepe Üniversitesi Tıp Fakültesi, Enfeksiyon Hastalıkları ve Klinik Mikrobiyoloji Anabilim Dalı, İstanbul.
}

\begin{abstract}
ÖZET
Üriner sistem enfeksiyonu (ÜSi்) klinik pratikte en sık karșılaşılan enfeksiyonlardandır. Bu çalışmada, ÜSİ etkenlerinin ve antimikrobiyal duyarlılıklarııı incelenmesi ve ampirik tedavide sıkça kullandığımız antibiyotikeri gözden geçirmek amaçlanmışıı. Ocak 2018-Aralık 2019 tarihlerinde, hastanemiz klinik mikrobiyoloji laboratuvarına ÜSİ ön tanısı ile gönderilen idrarlar incelendi. Üropatojenlerin identifikasyonu ve antibiyotik duyarlılıkları tam otomatize sistemle belirlendi. ÜSİ tanısı olan hastalardan izolen edilen 537 (\%68,5 ayaktan ve \%31,5 yatan hastalardan elde edilen) üropatojen arasında E.coli $(\% 66,5)$ en sık etkendi. Gram-negatif bakterilerde genişlemiş spektrumlu beta-aktamaz (GSBL) üretimi \%14,9 oranında saptandı. Antibiyotiklere duyarlılıkları incelendiğinde; siprofloksasin ve trimetoprim-sulfametoksazol için $\% 40$, sefuroksim için $\% 50$, gentamisin için $\% 17$, nitrofurantoin için $\% 15$ ve fosfomisin için $\% 6$ civarında direnç saptandı. Direnç oranları, yatarak tedavi gören hastalarda anlamlı olarak daha yüksekti. Üropatojenlerde direnç artışı tedavide önemli bir sorundur. Bölgesel antibiyotik duyarlııklarının bilinmesi, akılcı antibiyotik kullanımı için önem arz eder. Tedavide kinolon kullanımından kaçınılmalıdır. Komplike olmayan üriner sistem enfeksiyonlarında nitrofurantion ve fosfomisin kullanımı güvenli olacaktır.
\end{abstract}

Anahtar Kelimeler: Üriner sistem enfeksiyonu. Antibiyotik. Direnç.

Antibiotic Resistance in Uropathogens: Are the Most Frequently Used Agents Effective?

\begin{abstract}
Urinary system infection (UTI) is one of the most common infections in clinical practice. In this study, we aimed to examine the UTI agents and their antimicrobial susceptibility and to evaluate the antibiotics we use frequently in empirical treatment. The urine samples obtained from patients diagnosed with UTI were analyzed at the clinical microbiology laboratory of our hospital (from January 2018 to December 2019). A fully automated system was used to identify uropathogens and determine antibiotic susceptibilities. Among 537 (68.5\% outpatients and $31.5 \%$ inpatients) isolates were evaluated. E.coli (66.5\%) was the most common uropathogen. Extended spectrum beta-lactamase (ESBL) production was found in $14.9 \%$ of Gram-negative bacteria. The analysis of the antibiotic susceptibility test results indicated that resistance to ciprofloxacin and trimethoprim-sulfamethoxazole was $40 \%$, cefuroxime was $50 \%$, gentamicin was $17 \%$, nitrofurantoin was $15 \%$ and fosfomycin was $6 \%$, approximately. Resistance rates were found to be significantly higher in inpatients. Increased resistance rates in uropathogens is a serious problem for UTI treatment. It is important to know the local antibiotic resistance patterns for rational antibiotic use. The use of quinolone should be avoided for empiric treatment. Nitrofurantoin and fosfomycin use will be safe in uncomplicated urinary tract infections.
\end{abstract}

Key Words: Antibiotic. Resistance. Urinary tract infection.

Geliş Tarihi: 05.Ocak.2021

Kabul Tarihi: 22.Şubat.2021

Dr. Aslı KARADENIZ

Enfeksiyon Hastalıkları ve Klinik Mikrobiyoloji Anabilim Dalı, Maltepe Üniversitesi Tıp Fakültesi Hastanesi,

Feyzullah Cad. No: 39,

İstanbul.

Tel: 05324242937

E-posta: asli.karadeniz@maltepe.edu.tr

Yazarların ORCID ID Bilgisi:

Aslı KARADENIZ: 0000-0003-3799-1090

Aziz Ahmad HAMIDi: 0000-0003-4108-0847
Üriner sistem enfeksiyonu (ÜSİ) klinikte toplum kaynaklı ve nozokomiyal en sık karşılaştığımız enfeksiyonlardan biridir. Bu enfeksiyonlardan çoğunlukla Gram-negatif bakteriler sorumludur; Esherichia coli dünya genelinde en sık saptanan etkendir. Üropatojenlerde antibiyotik duyarlılıkları çeşitli faktörlere bağlı olarak bölgesel farklar göstermektedir. Ampirik tedavi seçiminde bölgesel direnç durumunu bilmek akılcı antibiyotik kullanımı ve antibiyotik direncini azaltmaya katkı sağlar ${ }^{1-4}$.

\section{Gereç ve Yöntem}

Maltepe Üniversitesi Tıp Fakültesi Hastanesi Mikrobiyoloji Laboratuvarında, Ocak 2018- Aralık 2019 
tarihleri boyunca ÜSİ ön tanısı ile ayaktan ve yatan hastalardan gönderilen idrar kültürleri retrospektif olarak değerlendirildi. Steril şekilde alınan orta akım idrarı örnekleri, \%5 koyun kanlı agar ve "Eosin Metylene blue” (EMB) agar besiyerlerine ekilerek, $37^{\circ} \mathrm{C}$ 'de 18-24 saat aerob koşullarda inkübasyon sonrası $100.000 \mathrm{koloni} / \mathrm{ml}$ tek tip üreme olan idrarlar çalışmaya dahil edildi. İzole edilen suşların idenifikasyonu ve antibiyotik duyarlılıklarının belirlenmesinde tam otomatize sistem (VITEK 2, bioMerieux-Fransa) kullanıld1. Antibiyotik duyarlılıkları "European Committee on Antimicrobial Susceptibility Testing” (EUCAST) standartlarına uygun olarak yorumlandı. Üropatojen olmayan etkenler çalışmadan çıkarıldı. Birden fazla örneği olan hastanın, ilk üreyen örneği çalışmaya alınarak sonraki kültür sonuçları çalıșmadan çıkarıldı. Üropatojenlerin antibiyotik duyarlılıkları incelenerek, genişlemiş spektrumlu beta-laktamaz (GSBL) üretimi, karbapenem, siprofloksasin, trimetoprimsulfametoksazol (TMP-SMX), gentamisin, fosfomisin, sefuroksim ve nitrofurantoin duyarlıkları değerlendirildi. Ayaktan ve yatan hastalardaki dağılımı karşılaştırıldi.

Veriler yüzde ve sayı olarak ifade edildi. Verilerin istatistiksel analizi için, SPSS Version 15.0 (SPSS Inc., Chicago, ABD) paket programı kullanıldı. Tanımlayıc1 istatistikler, ortalama, standart sapma, kategorik değişkenlerin oranların arasındaki farklılığın anlamlılığının değerlendirilmesi için Ki-Kare testi kullanıldı. İstatistiksel anlamlılık için $\mathrm{p}<0.05$ kabul edildi.

Maltepe Üniversitesi Klinik Araştırmalar Etik Kurulundan etik kurul onayı alındı (23.09.2020 tarih 461 no).

\section{Bulgular}

Çalıșmamızda, 2 yıllık süreçte laboratuvarımıza gönderilen 2324 idrar örneği incelendi. ÜSİ tanısı olan hastalardan izole edilen $537(\% 23,1)$ etken çalışmaya alınd. Bu etkenlerin \%68,5'i (368 etken) ayaktan ve \%31,5’i (169 etken) klinikte yatan hastalardan elde edildi. Ayaktan olan olgularda, 344 hastadan Gramnegatif çomak, 20 hastadan Enterococcus spp. ve dört olgudan Pseudomonas aeruginosa izole edildi. Yatan hastalarda, 121 olguda Gram-negatif çomak, 26 olguda Enterococcus spp. ve 12 hastada non-fermentatif Gram-negatif çomak üredi. E.coli, ÜSİ'de en sik $(\% 66,5)$ etken olarak saptand1. Her iki grupta E. coli en s1k saptanan etken olmakla birlikte; Klebsiella spp., E. feacium, ve P.aeruginosa suşlarının yatan hastalarda sıklığı artmış bulundu. Etkenlerin ayaktan ve yatan hasta gruplarındaki dağılımı Tablo I'de özetlenmiştir. Gram-negatif üropatojenlerde direnç; siprofloksasinde \%40,7, TMP-SMX'de \%38, gentamisinde \%17, sefuroksimde \% 50,3, nitrofurantoinde $\% 15,5$ ve fosfomisinde $\% 6,1$ olarak saptandı. GSBL oranı tüm etkenlerde \%14,9 ve E.coli suşlarında \%14 olarak saptandı. E.fecalis suşlarında penisiline direnç saptanmazken E. feacium suşlarında bu direnç ayaktan olan hastalarda \%40, yatan hastalarda \%93,3 bulundu. GSBL pozitifliği ve direnç oranları Tablo II ve III'te sunulmuştur. Yatan ve ayaktan hastalar karşılaştırıldığında, yatan hastalardaki etkenlerde antibiyotik direnç oranları istatistiksel açıdan anlamlı olarak daha yüksekti (Tablo IV).

Tablo I. Etkenlerin dağ $11 ı m ı$

\begin{tabular}{|llll|}
\hline Etkenler (\%) & Ayaktan & Yatan & $\mathrm{p}$ \\
\hline \hline E.coli & 74.4 & 48.5 & $<0.001$ \\
Klebsiella spp. & 13.3 & 21.3 & $\mathbf{0 . 0 1 9}$ \\
E. fecalis & 4.1 & 6.5 & 0.223 \\
E. feacium & 1.3 & 7.9 & $<0.001$ \\
Proteus spp. & 2.7 & 5.3 & 0.129 \\
P. aeruginosa & 1.1 & 4.7 & $\mathbf{0 . 0 0 8}$ \\
Acinetobacter spp. & - & 2.4 & - \\
Diğer Gram negatifler & 2.7 & 2.4 & 0.813 \\
\hline
\end{tabular}

Tablo II. Ayaktan gelen hastalardan izole edilen etkenlerin direnç oranları

\begin{tabular}{|c|c|c|c|c|c|c|c|c|c|c|}
\hline Etkenler ( $n=368)$ & n (\%) & GSBL (\%) & $\begin{array}{c}\text { Penisilin } \\
\text { direnci (\%) }\end{array}$ & $\begin{array}{c}\text { Meropenem } \\
\text { direnci (\%) }\end{array}$ & $\begin{array}{l}\text { CiPdirenci } \\
(\%)\end{array}$ & $\begin{array}{c}\text { TMP-SMX } \\
\text { direnci } \\
(\%)\end{array}$ & $\begin{array}{c}\text { Genta } \\
\text { direnci (\%) }\end{array}$ & $\begin{array}{c}\text { F } \\
\text { direnci } \\
(\%)\end{array}$ & $\begin{array}{c}\text { CXM } \\
\text { direnci } \\
(\%)\end{array}$ & $\begin{array}{l}\text { NF } \\
(\%)\end{array}$ \\
\hline E.coli & $275(74.7)$ & $34(12.4)$ & - & $1(0.4)$ & $100(36.4)$ & $100(36.4)$ & $34(12.4)$ & $2(0.7)$ & $134(48.7)$ & $12(4.4)$ \\
\hline Klebsiella spp. & 49 (13.3) & $1(2.0)$ & - & $0(0)$ & $4(8.2)$ & $7(14.3)$ & $1(2.0)$ & $10(20.4)$ & $10(20.4)$ & $18(36.7)$ \\
\hline E. fecalis & $15(4.1)$ & - & $0(0)$ & - & $9(60.0)$ & $9(60.0)$ & - & - & - & \\
\hline E. feacium & $5(1.3)$ & - & $2(40.0)$ & - & $5(100)$ & $2(40.0)$ & - & - & - & \\
\hline Proteus spp. & $10(2.7)$ & $2(20.0)$ & - & $0(0)$ & $1(10.0)$ & $2(20.0)$ & $0(0)$ & $0(0)$ & $2(20)$ & $10(100)$ \\
\hline P. aeruginosa & $4(1.1)$ & - & - & $0(0)$ & $1(25.0)$ & - & $0(0)$ & - & - & \\
\hline $\begin{array}{l}\text { Diğer Gram-negatif } \\
\text { bakteriler }\end{array}$ & $10(2.7)$ & $7(70.0)$ & - & $0(0)$ & $0(0)$ & $0(0)$ & $1(10.0)$ & $1(10.0)$ & $6(60)$ & $3(30)$ \\
\hline Toplam & $368(100)$ & *44 (12.9) & **2 (10) & $*_{1}(0.3)$ & $120(32.6)$ & $120(33.0)$ & *36 (10.3) & $13(3.8)$ & $152(44.4)$ & $43(12.3)$ \\
\hline
\end{tabular}




\section{Üropatojenlerde Antibiyotik Direnci}

Tablo III. Yatan hastalardan izole dilen etkenlerin direnç oranları

\begin{tabular}{|c|c|c|c|c|c|c|c|c|c|c|}
\hline Etkenler ( $n=169$ ) & n (\%) & $\begin{array}{c}\text { GSBL } \\
(\%)\end{array}$ & $\begin{array}{c}\text { Penisilin } \\
\text { direnci (\%) }\end{array}$ & $\begin{array}{c}\text { Meropenem } \\
\text { direnci (\%) }\end{array}$ & $\begin{array}{c}\text { CiP } \\
\text { direnci (\%) }\end{array}$ & $\begin{array}{c}\text { TMP-SMX } \\
\text { direnci } \\
(\%)\end{array}$ & $\begin{array}{c}\text { Genta } \\
\text { direnci } \\
(\%)\end{array}$ & $\begin{array}{c}F \\
\text { direnci (\%) }\end{array}$ & $\begin{array}{c}\text { CXM } \\
\text { direnci } \\
(\%)\end{array}$ & $\begin{array}{l}\text { NF direnci } \\
\text { (\%) }\end{array}$ \\
\hline E.coli & $82(48.5)$ & $16(19.5)$ & - & $4(4.8)$ & $53(64.6)$ & $50(60.9)$ & $27(32.9)$ & $4(4.9)$ & $58(70.7)$ & $3(3.6)$ \\
\hline Klebsiella spp. & $36(21.3)$ & $11(30.5)$ & - & $10(27.8)$ & $30(83.3)$ & $20(55.5)$ & $12(33.3)$ & $10(27.8)$ & $30(83.3)$ & $21(58.3)$ \\
\hline E. fecalis & $11(6.5)$ & - & $0(0)$ & - & $8(72.7)$ & $9(81.8)$ & - & - & - & - \\
\hline E. feacium & $15(8.9)$ & - & 14 (93.3) & - & $14(93.3)$ & $12(80.0)$ & - & - & - & - \\
\hline Proteus spp. & $9(5.3)$ & $0(0)$ & - & $0(0)$ & $3(33.3)$ & $3(33.3)$ & $2(22.2)$ & $1(11.1)$ & $3(33.3)$ & $8(88.8)$ \\
\hline P. aeruginosa & $8(4.7)$ & - & - & $3(37.5)$ & $3(37.5)$ & - & $2(55.0)$ & - & & \\
\hline Acinetobacter spp. & $4(2.4)$ & - & - & $3(75.0)$ & $3(75.0)$ & $3(75.0)$ & $3(75.0)$ & - & & \\
\hline $\begin{array}{l}\text { Diğer gram negatif } \\
\text { bakteriler }\end{array}$ & $4(2.4)$ & $4(100)$ & - & $0(0)$ & $2(50.0)$ & $2(50.0)$ & $1(25.0)$ & $2(50.0)$ & $4(100)$ & $1(25)$ \\
\hline Toplam & $169(100)$ & *36 (29.7) & **14 (53.8) & *20 (13.9) & $116(68.6)$ & $99(58.6)$ & *47 (32.8) & *17 (14.0) & $95(78.5)$ & $33(27.2)$ \\
\hline
\end{tabular}

Tablo IV. Direnç oranlarının ayaktan ve yatan hastalarda karşılaştırılması

\begin{tabular}{|c|c|c|c|}
\hline Direnç oranı (\%) & Ayaktan & Yatan & $p$ \\
\hline GSBL direnci & 12.9 & 29.7 & $<0.001$ \\
\hline $\begin{array}{l}\text { Gram negatiflerde karbape- } \\
\text { nem direnci }\end{array}$ & 0.3 & 13.9 & $<0.001$ \\
\hline $\begin{array}{l}\text { Tüm etkenlerde siprofloksa- } \\
\text { sin direnci }\end{array}$ & 32.6 & 68.6 & $<0.001$ \\
\hline $\begin{array}{l}\text { Tüm etkenlerde TMP-SMX } \\
\text { direnci }\end{array}$ & 33.0 & 61.5 & $<0.001$ \\
\hline $\begin{array}{l}\text { Gram-negatiflerde gentami- } \\
\text { sin direnci }\end{array}$ & 10.3 & 32.8 & $<0.001$ \\
\hline $\begin{array}{l}\text { Gram-negatiflerde fosfomisin } \\
\text { direnci }\end{array}$ & 3.8 & 14.0 & $<0.001$ \\
\hline $\begin{array}{l}\text { Enterokoklarda penisilin } \\
\text { direnci }\end{array}$ & 10 & 53.8 & 0.002 \\
\hline Sefuroksim direnci & 44.4 & 78.5 & $<0.001$ \\
\hline Nitrofurantoin direnci & 12.3 & 27.2 & $<0.001$ \\
\hline
\end{tabular}

\section{Tartışma ve Sonuç}

ÜSİ dünya genelinde önemli ölçüde morbiditeye ve bakteriyemi varlığında mortaliteye nedeni olduğu bilinen enfeksiyonlardandır ${ }^{1-5}$. ÜSI'de E.coli (ülkemizde yapılan çalışmalarda \%70-95) en sık etkendir ${ }^{6}$. Çalışmamızda etken patojenler arasında E.coli sıkl1$\breve{g} 1 \% 66,5$ olup bu ülkemiz verileri uyumludur.

ÜSI'de kinolonlar, TMP-SMX, beta-laktam antibiyotikler, nitrofurantoin ve fosfomisin rehberlerde ampirik tedavide kullanımı önerilen antibiyotiklerdir, ancak antibiyotiklere zaman içerisinde artan direnç tedavide sorun yaratmaktadır ${ }^{1-6}$. Üropatojenlerde GSBL üretimi de özellikle son 10-15 yıl içinde artı̧ gösteren önemli bir direnç problemidir. GSBL direncini kodlayan plazmidler kinolonlar, aminoglikozidler gibi diğer antibiyotiklere direnç genlerini de taşır. Bu durum, karbapenem grubu antibiyotik kullanımının artmasına yol açmaktadır ${ }^{7-10}$. Ülkemizdeki çalışmalarda GSBL oranının \%10-30 arasında olduğu, GSBL üreten bakterilerde antibiyotiklere direnç oranlarının arttığı ve kinolon ile TMP-SMX dirençlerinin yüksek oranlarda saptandığı bildirilmiştir ${ }^{7-9}$. Duman ve arkadaşlarının GSBL oranını yatan hastalarda $\% 27,5$ ve ayaktan hastalarda $\% 13,9$ olarak saptadığı çalışma ${ }^{11}$ ile benzer şekilde çalışmamızda GSBL oranı, ayaktan hastalarda $\% 13$ ve yatan hastalarda $\% 30$ civarında saptanmıştır.

Kinolonlar ÜSİ tedavisinde patojenlere etkinliği bilinen, üriner sisteme geçişi iyi olan antibiyotik grubu olmakla birlikte, son yıllarda kinolonlara direnç artmıştır,7,11. Kinolon kullanımı ile direnç artışının paralel olduğu gösterilmiştir. Türkiye'de kinolonlar için 1990'larda \%10'un altında olan direnç oranlarının yaygın kullanıma bağlı olarak 2000'lerde \%37'ye yükseldiği gösterilmiştir ${ }^{12}$. Çeşitli çalışmalarda ülkemizde \%20-40 civarında görülen kinolon direnci, Öztürk ve arkadaşlarının çalışmasında ayaktan hastalarda \%44 ve yatan hastalarda \%73 bulunmuştur ${ }^{13}$. Çalışmamızda siprofloksasine direnç \%40,7 (yatan hastalarda \%69 ve ayaktan hastalarda \%33) saptanmıştır. Komplike olmayan piyelonefritli hastalarda, florokinolonlara direnç prevalansı toplumda \%10’u aşmıyorsa siprofloksasin ile yedi gün tedavi yeterli olduğu bildirilen yayınlar ${ }^{14,15}$ göz önünde bulundurulduğunda, yüksek direnç oranları nedeniyle kinolonların ampirik tedavide kullanımından kaçınılmalıdır.

Özellikle dirençli suşlarda artış ile tedavi seçenekleri sinırlı hale gelmektedir. Klinik pratikte, ayaktan tedavide kullanılacak antibiyotik veya oral tedavi seçeneği olmayan durumlarda, tek başına kullanılabildiği görülen aminoglikozidlere direnç oranlarında yine zaman içinde artış gözlenmiştir ${ }^{4}$. Gentamisin direnci ülkemizdeki çalışmalarda \%13-37 arasında değişmektedir $^{4,7,11}$; çalışmamızda $\% 17$ civarında saptanmıştır.

ÜSİ tedavisinde özellikle ayaktan tedavide sıkça kullanılan sefalosporinlerden sefuroksime direnç, Öztürk ve arkadaşlarının çalışmasında ${ }^{13}$ ayaktan hastalarda $\% 23$ ve yatan hastalarda $\% 61$ oranında saptanmıştır. 
Bizim çalışmamızda da yatan hastalarda (\%80) ayaktan başvuran hastalardan daha yüksek sefalosiporinlere direnç (\%44) mevcuttu. Duman ve arkadaşlarının çalışmasında ${ }^{11}$ yatan ve ayaktan hastalardaki \%48 civarındaki oranla benzer şekilde, çalışmamızda tüm suşlarda direnç $\% 50$ civarındadır. Bu oranlar, sefuroksimi ampirik tedavide ilk siralarda değerlendirmemek gerektiğini ortaya koymaktadır.

Amerika Birleşik Devletleri verilerinde, nitrofurantoine son 10 yılda direnç artışı olmadığı (\%92 duyarlı), fosfomisinin \%99 duyarlı olduğu bildirilmiştir, rehberler ışı̆̆ında, TMP-SMX'in duyarlı ise tedavide seçilebileceği, ampirik kullanımda lokal verilere dikkat edilmesi gerektiği vurgulanmıştır ${ }^{23}$. Direnç oranının \%20’yi aşmadığ 1 durumlarda, rehberlerde ${ }^{14,17}$ ampirik tedavide ilk tercih edilmesi önerilen TMPSMX için ülkemizde üropatojenlerde direnç oranları değișken (\%30-55) oranlarda bildirilmiștir ${ }^{3,9,10,11}$. ÜSI'de en sık saptanan etkenlerde TMP-SMX direncinin değerlendirildiği çalışmalarda ayaktan ve yatan hastalarda benzer oranlar saptanmıştır ${ }^{3,4,13}$. Çalışmamizda \%38 olarak saptanan TMP-SMX direnci, yatan hastalarda $\% 60$ ve ayaktan hastalarda $\% 30$ civarındaki oranlarla anlamlı olarak farklı bulunmuştur.

Komplike olmayan ÜSİ tedavisinde önerilen fosfomisin için direnç, dünya genelinde $\% 0-19$, ülkemizde \%0-11.5 civarında (çoğu çalışmada \%1'in altında) saptanmıştır ${ }^{9,18,19}$. Fosfomisin direncini \%8.6 saptayan Sönmezer ve arkadaşlarının çalışmasında ${ }^{20}$ belirtildiği gibi, farklı oranlar; coğrafi bölge, hasta popülasyonunun özellikleri, çalışmanı yapıldığı yıllar gibi bir çok faktöre bağlı olabilir. Çalışmamızda \%6 (ayaktan hastalarda $\% 4$, yatan hastalarda \%14) oranındaki fosfomisin direnci çoğu çalışmalardaki oranlardan hafif yüksek olsa da fosfomisin komplike olmayan enfeksiyonlar için en uygun seçeneklerden biri olarak belirmektedir.

Nitrofurantoin için, gelişmekte olan ülkelerde E.coli suşlarında direnç oranı \%27, diğer Gram-negatif çomaklarda \%50 civarında saptanmıştır ${ }^{21,22}$. Ülkemizde nitrofurantoin için direnç oranları çeşitli çalışmalarda \%3-35 oranındadır ${ }^{5,19}$. Ayaktan tedavide sıkça tercih edilen nitrofurantoin \%15 (ayaktan hastalarda \%12, yatan hastalarda \%27) direnç oranı ile, tedavide seçilmesi uygun bir ilaçtır.

Çalışmalarda yatan hastalardaki direnç oranları, bir çok faktöre bağlı olarak, ayaktan hastalara oranla daha yüksektir ${ }^{8,9}$. Özellikle yatan hastalarda, dirençli suşlarda ve GSBL varlığında en uygun tedavi olarak beliren karbapenemler için, artan karbapenemaz direnci günümüzde problem olmaktadır ${ }^{23}$. Çalışmamızda E.coli suşlarında (ayaktan ve yatan hastalarda \%0,4 ve $\% 4,8)$ ve Klebsiella suşlarında (\%0 ve \%27,8) oranındaki meropenem direnci Çaskurlu ve arkadaşlarının $^{5}$ saptadığ (E.coli için \%0,3 ve Klebsiella spp. için \%2,8) oranlara kıyaslandığında yatan hasta örneklerinde nispeten yükseklik göstermekle birlikte, kar- bapenemlerin komplike enfeksiyonların tedavisinde etkinliklerini koruduğu görülmektedir.

Sonuç olarak, hastanede yatan hastalarda dirençli bakterilerin izole edilme oranları artmaktadır. Düzenli sürveyanslarla antibiyotik direnç profilinin belirlenmesi, tedavi yaklaşımlarının direnç profiline göre şekillendirilmesi için önemlidir.

\section{Etik Kurul Onay Bilgisi:}

Onaylayan Kurul: Maltepe Üniversitesi Klinik Araştırmalar Etik Kurulu.

Onay Tarihi: 23.09.2020

Karar No: 461

\section{Araştırmacı Katkı Beyanı:}

Fikir ve tasarım: A.K., A.A.H.; Veri toplama ve işleme: A.K., A.A.H.; Analiz ve verilerin yorumlanması: A.K., A.A.H.; Makalenin önemli bölümlerinin yazılması: A.K., A.A.H.

Destek ve Teşekkür Beyanı:

Biyolog Seher Gürlü’ye patojenlerin antimikrobiyal duyarll1ık testleri çalışması aşamasında verdiği destek için teşekkür ederiz. Çıkar Çatışması Beyanı:

Makale yazarlarının çıkar çatışması beyanı yoktur.

\section{Kaynaklar}

1. Pezeshki Najafabadi M, Dagoohian A, Rajaie S, ZarkeshEsfahani SH, Edalati M. Common microbial causes of significant bacteriuria and their antibiotic resistance pattern in the Isfahan Province of Iran. J Chemother. 2018 Oct;30(6-8):348-53.

2. Bader MS, Loeb M, Leto D, Brooks AA. Treatment of urinary tract infections in the era of antimicrobial resistance and new antimicrobial agents. Postgrad Med. 2019 Oct 24;1-17.

3. Temiz H, Akkoç H, Gül K. Laboratuarımızda idrar kültürlerinden izole edilen Gram negatif bakterilerde antibiyotiklere direnç. Dicle Tıp Derg 2008; 35: 234-9.

4. Budak S, Sarı U, Aksoy E, ve ark. Üriner sistem infeksiyonlarına yol açan bakterilerin dağılımı ve E. coli için antibiyotik direnç oranlarının incelenmesi. Yeni Üroloji Dergisi. 2015;10(1):21-4.

5. Caskurlu H, Culpan M, Erol B, Turan T, Vahaboglu H, Caskurlu T. Changes in antimicrobial resistance of urinary tract infections in adult patients over a 5-year period. Urol Int. 2020;15:16 .

6. Avcıoğlu F, Behçet M. Üriner sistem enfeksiyonu etkeni Escherichia coli izolatlarının çeşitli antibiyotiklere direnç oranlarının değerlendirilmesi. Turk Mikrobiyol Cem Derg 2020;50(3):1727

7. Aykan SB, Ciftci IH. Antibiotic resistance patterns of Escherichia coli strains isolated from urine cultures in Turkey: a metaanalysis. Mikrobiyol Bul. 2013;47:603-18.

8. Alpay Y, Yavuz MT, Aslan T, Büyükzengin B. Can oral antibiotics be an alternative to carbapenems in the treatment of noncomplicated urinary tract infections caused by extendedspectrum beta-lactamase positive Escherichia coli? ANKEM Derg 2017;31(3):85-91

9. Karamanlığlu D, Aysert-Yıldız P, Kaya M, Sarı N. Extendedspectrum $\beta$-lactamase production rates and antibiotic susceptibilities among Enterobacteriaceae isolated from urine. Klimik Derg. 2019; 32(3): 233-9.

10. Mert D, Çeken S, Ertek M. İdrar yolu enfeksiyonlarında kültürden izole edilen bakteriler ve antibiyotik duyarlılıkları. Turk Hij Den Biyol Derg, 2020; 77(1): 25-32.

11. Duman Y, Güçlüer N, Serindağ A, Tekerekoğlu MS. Escherichia coli suşlarında antimikrobiyal duyarlılık ve Genişlemiş 


\section{Üropatojenlerde Antibiyotik Direnci}

Spektrumlu-Beta Laktamaz (GSBL) varlığı Fırat Tıp Dergisi 2010;15(4): 197-200

12. Karaca Y, Coplu N, Gozalan A, Oncul O, Citil BE, Esen B. Cotrimoxazole and quinolone resistance in Escherichia coli isolated from urinary tract infections over the last 10 years. Int $J$ Antimicrob Agents 2005;26(1):75-7.

13. Öztürk Mİ, Koca O, Kalkan S, ve ark. Üroloji kliniklerinde görülen patojenlere karșı antimikrobiyal direncin güncel durumu. Türk Üroloji Dergisi 2008;34:363-7.

14. Gupta K, Hooton TM, Naber KG,et al; Infectious Diseases Society of America; European Society for Microbiology and Infectious Diseases. Clin Infect Dis 2011; 52(5):103-20

15. Picozzi S, Ricci C, Gaeta $M$, et al. Do we really know the prevalence of multi-drug resistant Escherichia coli in the territorial and nosocomial population? Urol Ann 2013 Jan;5(1):259.

16. Waller TA, Pantin SAL, Yenior AL, Pujalte GGA. Urinary tract infection antibiotic resistance in the United States. Prim Care. 2018 Sep;45(3):455-66.

17. Mazzulli T. Diagnosis and management of simple and complicated urinary tract infections (UTIs). Can J Urol 2012;19 Suppl 1:42-8.

18. İrvem A, Küçük EV, Pala E ve ark. Üriner sistem enfeksiyonlarından izole edilen Escherichia coli suşlarında fosfomisin tro- metamol duyarlılığının araştırılması. Türk Mikrobiyol Cem Derg 2015; 45(2):88-91

19. Denk A, Tartar AS. İdrar kültürlerinden izole edilen toplum kökenli escherichia coli suşlarında antibiyotik direnci F.Ü. Sağ. Bil. Tip Derg 2015; 29 (2): 51 - 55

20. Sönmezer MÇ, Tülek N, Köksal E, Temoçin F, Ertem G, Erdinç FŞ. Toplum Kökenli Üriner Sistem İnfeksiyonlarında Etken Olan Genişlemiş Spektrumlu Beta-Laktamaz Üreten Escherichia coli İzolatlarında Fosfomisin Trometamolün İn Vitro Etkinliği. FLORA 2016;21(4):153-158

21. Mandal J, Acharya NS, Buddhapriya D, Parija SC. Antibiotic resistance pattern among common bacterial uropathogens with a special reference to ciprofloxacin resistant Escherichia coli. Indian J Med Res 2012;136(5):842-9.

22. Beyene G, Tsegaye W. Bacterial uropathogens in urinary tract infection and antibiotic susceptibility pattern in jimma university specialized hospital, southwest ethiopia. Ethiop $J$ Health Sci 2011;21(2):141-6.

23. Karadoğan E, Sümer S, Demir Na, Ural O. Toplum ve hastane kökenli genișlemiş spektrumlu beta-laktamaz üreten escherichia coli ve klebsiella pneumoniae ile oluşan üriner sistem enfeksiyonlarında risk faktörleri ve tedavi yaklașımları Nobel Med 2016; 12(3): 67-72 
